\title{
Autonomic dysfunction and severe hypoglycaemia in insulin dependent diabetes mellitus
}

\author{
L Barkai, L Madácsy, I Vámosi
}

\begin{abstract}
The aims of the present study were to investigate the relationship between severe hypoglycaemia and autonomic dysfunction in diabetic children, and to assess the glycaemic response to an insulin infusion test. In a one year period, 12 of 69 diabetic patients $(17 \%)$ experienced at least one severe episode of hypoglycaemia, defined as an event which required outside assistance. All patients underwent five cardiovascular autonomic tests. Seven of the hypoglycaemic patients showed three or more abnormal autonomic tests. Among the 57 non-hypoglycaemic diabetics, there was no patient with three or more abnormal tests. In hypoglycaemic diabetics with and without autonomic dysfunction, and in eight healthy age matched subjects an insulin infusion test was performed. A pronounced blood glucose decline and a subnormal increase in heart rate during insulin infusion were obtained in patients with autonomic dysfunction. Thus, severe hypoglycaemia may be due to impaired defence mechanisms against blood glucose decline in diabetic children with autonomic dysfunction.
\end{abstract}

Hypoglycaemia represents a constant risk for all patients with insulin dependent diabetes mellitus. ${ }^{1-3}$ Until recently, hypoglycaemia was considered as an acute event of inadequate diabetes management with no long term consequences. However, recent studies report that irreversible brain damage or intellectual impairment may be the consequence of severe hypoglycaemia. ${ }^{4-6}$ Currently available data indicate that severe hypoglycaemic episodes not infrequently accompany conventional insulin treatment and are even more frequent in patients receiving intensified insulin regimens. ${ }^{178}$ Nevertheless, little information is available concerning such episodes in children with diabetes.

There are a number of well established reasons which may explain why diabetic patients run into severe hypoglycaemic episodes. Poor compliance with injection technique, inappropriate insulin dosing with respect to meals and physical activity, and a recent change of insulin dose are factors known to precipitate hypoglycaemia $^{9}{ }^{10}$; however, one study reported that no cause could be defined in over one third of patients. ${ }^{11}$ One assumption is that autonomic nervous system dysfunction may be responsible for increased risk of severe hypoglycaemia, as autonomic activation plays an important role in defence mechanisms against hypoglycaemia. ${ }^{12-16}$ In this respect, the importance of disturbed autonomic function is not yet clear in childhood diabetes.

The aims of our present study were to investigate the relationship between severe hypoglycaemia and autonomic nervous system dysfunction in diabetic children treated conventionally with insulin and studied prospectively, and to assess the glycaemic response to an insulin infusion test. With this purpose, we included only those episodes of severe hypoglycaemia that caused loss of consciousness or convulsions and required outside assistance.

\section{Patients and methods}

Sixty nine children with insulin dependent diabetes mellitus who had been treated conventionally with insulin (two injections per day) since the onset of disease were considered for inclusion in this study. This represented $58 \%$ of the diabetic children seen in our clinic during the study period. All patients were receiving highly purified porcine insulin (Actrapid MC and Monotard MC, Novo-Nordisk) but no other medications. All were healthy except for diabetes, having negligible basal $\mathrm{C}$ peptide secretion (fasting $C$ peptide concentration $<0 \cdot 1$ $\mathrm{nmol} / \mathrm{l}$ ). The study was conducted prospectively over one year, the patients being seen at our clinic every two months. At each clinic visit, detailed information was obtained from the children and their parents on any episode of severe hypoglycaemia that had occurred since the last visit. Patients were requested to come to the clinic or contact the physician immediately in the event of severe hypoglycaemia, which was defined as loss of consciousness or convulsions and requiring outside assistance. Children with one or more episodes of severe hypoglycaemia during the study period were compared with a non-hypoglycaemic population (table 1). Comparisons between the groups were made by sex, age, duration of diabetes, fructosamine levels determined at each clinic visit, insulin doses, and autonomic function tests.

\section{AUTONOMIC FUNCTION TESTS}

Five cardiovascular tests were performed at the start of the prospective study, and one year later. Each diabetic child was examined in the lying position for the mean resting heart rate for a period of one minute, and for beat to beat variation during five maximal inspirations and expirations, for increase in heart rate and fall in systolic blood pressure during one minute standing after the lying position, and for rise in diastolic blood pressure after a one minute sus- 
Table 1 Characteristics of diabetic children with and without severe hypoglycaemia. Values are expressed as mean (SD)

\begin{tabular}{|c|c|c|c|}
\hline & \multicolumn{2}{|c|}{ Diabetic children } & \multirow[b]{2}{*}{$\begin{array}{l}\text { Total patients } \\
(n=69)\end{array}$} \\
\hline & $\begin{array}{l}\text { Hypoglycaemic } \\
(n=12)\end{array}$ & $\begin{array}{l}\text { Non-hypoglycaemic } \\
(n=57)\end{array}$ & \\
\hline $\begin{array}{l}\text { Hypoglycaemia (events/year) } \\
\text { Sex (M/F) } \\
\text { Age (years) } \\
\text { Duration of diabetes (years) } \\
\text { Mean fructosamine (mmol//) } \\
\text { Daily insulin dose (U/kg) }\end{array}$ & $\begin{array}{l}1 \cdot 25(0 \cdot 5) \\
4 / 8 \\
13 \cdot 4(3 \cdot 7) \\
6 \cdot 1(2 \cdot 6)^{*} \\
3 \cdot 3(0 \cdot 6) \\
0 \cdot 7(0 \cdot 3)\end{array}$ & $\begin{array}{l}0 \\
0 \\
24 / 33 \\
13 \cdot 8(3 \cdot 3) \\
3 \cdot 7(2 \cdot 4) \\
3 \cdot 8(0 \cdot 4) \\
0 \cdot 6(0 \cdot 2)\end{array}$ & $\begin{array}{l}0.22(0 \cdot 3) \\
28 / 41 \\
13 \cdot 7(3 \cdot 4) \\
4 \cdot 4(2 \cdot 5) \\
3.7(0 \cdot 4) \\
0.62(0.3)\end{array}$ \\
\hline
\end{tabular}

tained maximal handgrip. ${ }^{17-19}$ Heart rates were determined with a routine electrocardiographic device (Medicor ER 31-A) by R-R intervals in standard leads; for blood pressure measurements a digital blood pressure device (Omron HEM-400 C) was used. Test results at the start of the study and one year later did not differ significantly. Consequently all results were pooled.

To obtain a reference range of cardiovascular tests, 30 healthy, age matched children were used as a control group. Confidence intervals of 95\% (2 SD) from means of control subjects were considered as limits of normality. If the deviation from the mean in the control group exceeded 2 $\mathrm{SD}$, the values of the diabetic children were considered as abnormal. ${ }^{20}$

\section{INSULIN INFUSION TEST}

The hypoglycaemic patients and eight healthy children matched for age and weight were exposed to an intravenous insulin infusion test. Studies were performed after a 10 hour overnight fast. The patients took their last dose of regular insulin at $17.00 \mathrm{~h}$ followed by their usual meal at $17.30 \mathrm{~h}$ and a snack at $21.00 \mathrm{~h}$. Their evening dose of intermediate acting insulin was omitted. To maintain an overnight normoglycaemia in the diabetic subjects, variable rate intravenous infusions of insulin and glucose were started at $24.00 \mathrm{~h}$. The rates were adjusted according to frequent blood glucose measurements. At 07.00 $h$ a constant rate intravenous insulin infusion was started $(0.02 \mathrm{U} / \mathrm{kg} / \mathrm{h}$, Actrapid HM, NovoNordisk) and continued for three hours. Subjects were asked before the study to report immediately any symptoms that they thought might be due to hypoglycaemia. During the three hour constant rate insulin infusion period, capillary blood glucose concentration, heart rate, and blood pressure were determined at $\mathbf{3 0}$ minute intervals, and the skin was examined for signs of sweating. Venous blood samples were taken at 60 minute intervals for measurement of free insulin and blood glucose. All subjects gave their informed consent to the study which was approved by the local ethical committee.

\section{ANAL YTIC METHODS}

Capillary blood glucose concentrations were determined by means of a glucose reflectance meter (Ames Company, Division Miles Laboratories), and venous glucose concentrations were measured by the glucose oxidase method.
Serum fructosamine was measured by the Roche fructosamine kit. The mean (SD) for non-diabetic children was $2.0(0.3) \mathrm{mmol} / \mathrm{l}$. Fasting serum $\mathrm{C}$ peptide concentration was determined by the Mallincrodt kit (RIA-mat C peptide). The normal fasting value is $0.17-0.99$ $\mathrm{nmol} / \mathrm{l}$. Plasma for free insulin was treated with polyethylene glycol immediately after separation to precipitate antibody-bound insulin. The supernatant was then assayed within four weeks with a double antibody radioimmunoassay. The sensitivity of the assay is $0.3 \mathrm{mU} / 1$ with a coefficient of variation of $0 \cdot 04$.

\section{STATISTICAL ANALYSIS}

Data and results are expressed as mean (SD). Data were tested by Student's paired and unpaired $t$ tests. The frequency of cases with abnormal tests between groups was assessed by $\chi^{2}$ test with Yates's correction. The metabolic clearance rate was calculated as the ratio between the constant insulin infusion rate $\left(\mu \mathrm{U} / \mathrm{m}^{2} / \mathrm{min}\right)$ and the steady state, plasma free insulin concentration $(\mu \mathrm{U} / \mathrm{ml})$.

\section{Results}

Fifteen hypoglycaemic episodes were registered in $12(17 \%)$ patients, and $57(83 \%)$ diabetics had no hypoglycaemia during the one year study period (table 1). There were no significant differences in respect of sex distribution, age, metabolic control assessed by mean fructosamine concentrations, and insulin doses between the two diabetic groups. However, diabetic children with severe episodes of hypoglycaemia had diabetes of longer duration than patients without hypoglycaemia (table 1).

Three or more abnormal cardiovascular tests were obtained in seven of the 12 hypoglycaemic patients, whereas among the 57 non-hypoglycaemic diabetics there was no patient with three or more abnormal autonomic tests (7/12 v 0/57, $\mathrm{p}<0.001)$. The remaining five patients in the hypoglycaemic group had fewer than three abnormal cardiovascular tests. The two subgroups of hypoglycaemic patients (group A, three or more abnormal autonomic tests, and group B, fewer than three abnormal tests) are characterised in table 2. Sex distribution, age, diabetes duration, metabolic control, and insulin doses were comparable in groups A and $B$.

Blood glucose and heart rate responses to insulin infusion test as well as plasma free 
Table 2 Characteristics of hypoglycaemic diabetics with three or more (group A) and with fewer than three (group B) abnormal cardiovascular tests. Values are expressed as mean $(S D)$

\begin{tabular}{lcc}
\hline & \multicolumn{2}{l}{ Hypoglycaemic patients } \\
\cline { 2 - 3 } & $\begin{array}{l}\text { Group } A \\
(n=7)\end{array}$ & $\begin{array}{l}\text { Group } B \\
(n=5)\end{array}$ \\
\hline Hypoglycaemia (events/year) & $1.3(0.5)$ & $1 \cdot 2(0.5)$ \\
Sex (M/F) & $2 / 5$ & $2 / 3$ \\
Age (years) & $13.6(2.4)$ & $13.0(3.2)$ \\
Duration of diabetes (years) & $6.3(2.9)$ & $5.8(2.3)$ \\
Mean fructosamine (mmol/l) & $3.2(0.6)$ & $3.5(0.5)$ \\
Daily insulin dose (U/kg) & $0.73(0.3)$ & $0.66(0.3)$ \\
\hline
\end{tabular}

insulin profiles in the two groups of patients and in the healthy control group (group C) were compared. As shown in the figure, blood glucose concentrations were similar in the three groups of children before insulin infusion test. Glucose profiles during the insulin infusion test were similar in groups B and C, whereas group A showed a more pronounced glucose decline. The mean blood glucose concentration at glucose nadir was lower in group A than in groups B and $C(2.7(0.3) v 3.8(0.4)$ and $3.9(0.4) \mathrm{mmol} / \mathrm{l}$,
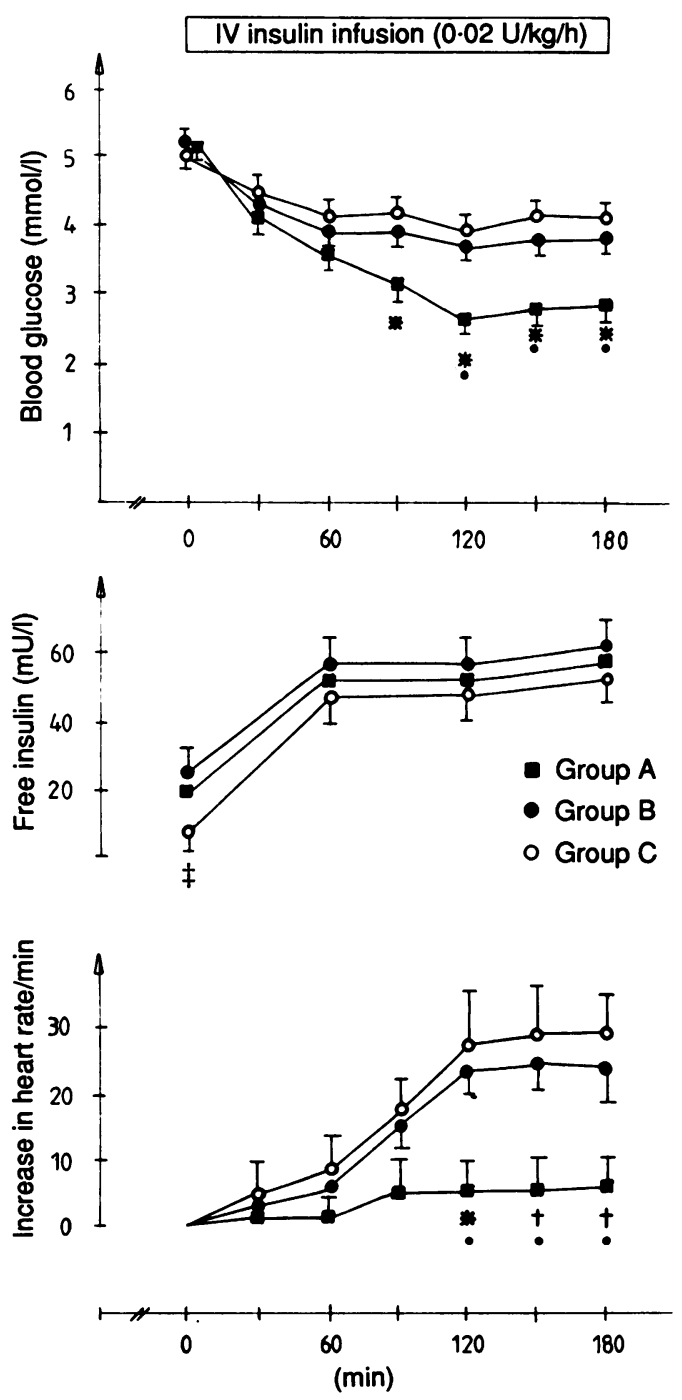

Blood glucose, plasma free insulin, and increase in heart rate during an intravenous (IV) insulin infusion test in patients with three or more (group A), with fewer than three (group B) abnormal cardiovascular tests, and in normál subjects (group $C$ ). ${ }^{*} p<0.01$, group $A v C ; \bullet p<0.01$, group $A v B$ $\neq p<0.001$, group $A v C ; \neq p<0.02$, group $C v A$ and $B$. $\mathrm{p}<0.01$ ). Group $\mathrm{C}$ had lower plasma free insulin concentrations than groups $\mathrm{A}$ and $\mathrm{B}$ before insulin infusion test (8 (3) $v 20$ (4) and 23 (5) $\mathrm{mU} / \mathrm{l}, \mathrm{p}<0.02)$. The steady state plasma free insulin concentrations were similar in the three groups. The metabolic clearance rates for insulin in groups A $\left(559(80) \mathrm{ml} / \mathrm{m}^{2} / \mathrm{min}\right), \mathrm{B}$ (542 (73) $\left.\mathrm{ml} / \mathrm{m}^{2} / \mathrm{min}\right)$ and $C\left(596(67) \mathrm{ml} / \mathrm{m}^{2} / \mathrm{min}\right)$ were not statistically different. The increase in heart rate during insulin infusion test was similar in groups B and C, whereas group A showed a subnormal heart rate increment $(5(6) v 24$ (7)/ $\min , \mathrm{p}<0.01$ and $30(5) / \mathrm{min}, \mathrm{p}<0.001)$. Significant change in blood pressure and increased sweating were not observed in any group studied. Hypoglycaemic symptoms, necessitating cessation of the insulin infusion, did not develop in any subject.

\section{Discussion}

In this study about $17 \%$ of diabetic children treated conventionally with insulin showed one or more severe hypoglycaemic episodes in a single year. This hypoglycaemic group had had diabetes for longer and had greater cardiovascular autonomic dysfunction than the nonhypoglycaemic group. Moreover, there was a relationship between autonomic dysfunction and abnormal glycaemic and heart rate responses to the insulin infusion test in hypoglycaemic patients.

Hypoglycaemia is the most frequent acute complication of insulin dependent diabetes mellitus. The incidence of severe hypoglycaemia in insulin dependent diabetes mellitus is controversial. Some studies report that the severity and frequency of hypoglycaemic episodes is related to the degree of blood glucose control and disease duration. ${ }^{18}$ In our present study overzealous attempts to achieve normoglycaemia can be excluded as a cause of severe hypoglycaemia because long term glycaemic control did not differ in those with and those without severe hypoglycaemia. However, overinsulinisation in our study may have played a part in a few subjects, but insulin dosages did not differ in those with and those without severe hypoglycaemia.

Hypoglycaemia in insulin dependent diabetic patients results from excessive insulin action, promoting the fall in blood glucose concentration to below the normal range. There are two physiological components of the hypoglycaemic response in both the normal and diabetic individual. The first is the complex of well known clinical signs of declining blood glucose concentration, resulting from autonomic activation. This phenomenon is known as hypoglycaemic awareness. The second component is biochemical in nature: with the decrease of blood glucose concentration, there is normally an increase in counter-regulatory hormone (glucagon, adrenaline) secretion leading to an immediate return of blood glucose concentration to the normal range. It is known that patients with insulin dependent diabetes may lose either their hypoglycaemic awareness, hormonal counter-regulation, or both. ${ }^{21-23}$ The mechanism for the loss of these defence systems 
is unclear. Many reports suggest that hypoglycaemia unawareness and impaired hormonal counter-regulation may be due to disturbed function of autonomic nerves as parasympathetic and sympathetic innervations play a part in glucagon and adrenaline secretion during hypoglycaemia. ${ }^{12-16}$ According to our previous study, dysfunction of autonomic nervous system may appear early during the course of childhood diabetes, ${ }^{20}$ and subclinical signs of autonomic neuropathy are demonstrable in a considerable proportion of diabetic children and adolescents. ${ }^{24}$ Our present study suggests that autonomic dysfunction, at least in part, may be responsible for severe hypoglycaemia in diabetic children. This is in agreement with a very recent study by Hepburn et $a l,{ }^{25}$ who found autonomic dysfunction and hypoglycaemia unawareness coexistently in patients with diabetes of short duration. Nevertheless, further studies are necessary to prove the exact relationship between autonomic dysfunction and impaired defence mechanisms against hypoglycaemia in diabetic children.

With the continuing application of intensified insulin regimens, the question has been raised about an increased risk of hypoglycaemic episodes as a result of the efforts to achieve normoglycaemia in diabetic children. Recurrent and severe hypoglycaemia may be as dangerous as the late complications of diabetes, therefore we have to make an attempt at identifying patients who are at increased risk. Cardiovascular tests may help to identify diabetic children and adolescents in whom intensified insulin treatment may be dangerous and requires more caution.

1 Goldstein DE, England JD, Hess R, Rawlings SS, Walker B. A prospective study of symptomatic hypoglycaemia in young diabetic patients. Diabetes Care 1981;4:601-5.

2 Muhlhauser I, Berger M, Sonnenberg G, et al. Incidence and management of severe hypoglycaemia in 434 adults with insulin-dependent diabetes mellitus. Diabetes Care 1985;8: 268-73.

3 Goldgewicht C, Slama G, Papoz L, Tchobrousky G. Hypoglycaemic reactions in 172 type 1 (insulin-dependent) diabetic patients. Diabetologia 1983;24:95-9.

4 Frier B. Hypoglycaemia and diabetes. Diabetic Med 1986;3: 513-25.
5 Soltesz G, Acsadi G. Association between diabetes, severe hypoglycaemia, and electroencephalographic abnormalities. hypoglycaemia, and electroence
Arch Dis Child 1989;64:992-6.

6 Ryan C, Atchison J, Puczynski S, Puczynski M, Arslanian S, Becker D. Mild hypoglycaemia associated with deterioration of mental efficiency in children with insulin-dependent tion of mental efficiency in children with insulititi
diabetes mellitus. F Pediatr 1990;117:32-8.

7 Daneman D, Frank M, Perlman K, Tamm J, Ehrlich R. Severe hypoglycaemia in children with insulin-dependent diabetes mellitus: frequency and predisposing factors. F Pediatr 1989;115:681-5.

8 The DCCT Research Group. Diabetes control and complications trial (DCCT): results of feasibility study. Diabetes Care 1987;10:1-19.

9 Nilsson A, Tideholm B, Kalén J, Katzman P. Incidence of severe hypoglycaemia and its causes in insulin-treated diabetics. Acta Med Scand 1988;244:257-62.

10 The DCCT Research Group. Diabetes control and complications trial (DCCT): design and methodologic considerations for the feasibility phase. Diabetes 1986;35:530-45.

11 Potter J, Clarke P, Gale EAM, Dave SH, Tattersall RB. Insulin-induced hypoglycaemia in an accident and emergency depa $1180-2$.

12 Hoeldtke RD, Guenther B, Shuman CR, Owen OE. Reduced epinephrine secretion and hypoglycaemia unawareness in diabetic autonomic neuropathy. Ann Intern Med 1982;96: 459-62.

13 Campbell LV, Kraegen EW, Lazarus L. Defective blood glucose counter-regulation in diabetics is a selective form of autonomic neuropathy. $B M \mathcal{F}$ 1977;ii:1527-9.

14 Maher TD, Tanenberg RI, Greenberg BZ, Hoffman JE, Doe RP, Goetz FC. Lack of glucagon response to hypo-
glycaemia in diabetic autonomic neuropathy. Diabetes 1977;26:196-200.

15 Palmer JP, Werner PL, Hollander P, Ensinck JW. Evaluation of the control of glucagon secretion by the parasymtion of the control of glucagon secretion by the parasym-
pathetic nervous system in man. Metabolism 1979;28: pathetic

16 Hilsted J, Madsbad S, Krarup T, et al. Hormonal, metabolic and cardiovascular responses to hypoglycaemia in diabetic
autonomic neuropathy. Diabetes $1981 ; 30: 626-33$.

17 Ewing DJ, Clarke BF. Diagnosis and management of diabetic autonomic neuropathy. BMF 1982;285:916-8.

18 Ewing DJ, Campbell IW, Clarke BF. Heart rate changes in diabetes mellitus. Lancet 1981;i:183-5.

19 Oikawa N, Umetsu M, Sakurada M, Sato H, Toyota T, Boto Y. Discrimination between cardiac para- and sympathetic damage in diabetics. Diabetes Res Clin Pract 1985;1:203-9.

20 Barkai L, Madácsy L, Kassay L. Investigation of subclinical signs of autonomic neuropathy in the early stage of childhood diabetes. Horm Res 1990;34:54-9.

21 Bolli GB, Dimitriadis GD, Pehling GB, et al. Abnormal glucose counterregulation after subcutaneous insulin in insulin-dependent diabetes mellitus. $N$ Engl $\mathcal{F} \mathrm{Med} 1984$; 310:1706-11.

22 White NH, Skor DA, Cryer PE, et al. Identification of type I diabetic patients at increased risk for hypoglycaemia during diabetic patients at increased risk for hypoglycaemia
intensive therapy. $N$ Engl f Med 1983;308:484-91.

23 Cryer PE, Binder C, Bolli GB, et al. Hypoglycaemia in IDDM. Diabetes 1989;38:1193-9.

24 Barkai L Jr, Madácsy L, Vincze P. Investigation of the relationship between autonomic neuropathy and retinal microangiopathy in diabetic children. Orv Hetil 1989;38: 2037-40.

25 Hepburn DA, Patrick AW, Eadington DW, Ewing DJ, Frier BM. Unawareness of hypoglycaemia in insulin-treated diabetic patients: prevalence and relationship to autonomic neuropathy. Diabetic Med 1990;7:711-7. 